\title{
EXPLORING UNIVERSITY STUDENTS' LEARNING EXPERIENCES IN THE COVID-19 SEMESTER THROUGH THE COMMUNITY OF INQUIRY FRAMEWORK
}

\author{
Dr. Mutlu SEN-AKBULUT \\ ORCID: 0000-0003-1042-2517 \\ Faculty of Education \\ Bogazici University \\ Istanbul, TURKEY \\ Dr. Duygu UMUTLU \\ ORCID: 0000-0002-2030-2626 \\ Faculty of Education \\ Bogazici University \\ Istanbul, TURKEY
}

Dr. Diler ONER

ORCID: 0000-0002-4817-3846

Faculty of Education

Bogazici University

Istanbul, TURKEY

Dr. Serkan ARIKAN

ORCID: 0000-0001-9610-5496

Faculty of Education

Bogazici University

Istanbul, TURKEY

Received: 10/01/2021 Accepted: 20/05/2021

\begin{abstract}
This mixed-method study was conducted to validate the factor structure of the Community of Inquiry (CoI) framework in the COVID-19 semester (Spring 2020). Spring 2020 is typically characterized as an emergency remote teaching (ERT) period, distinguished from purposefully-designed instruction for online teaching. To examine the CoI framework's usefulness for understanding university students' online learning experiences in this period, the authors collected data using the CoI survey and interviews. The structural equation modeling analyses indicated that teaching presence predicted social and cognitive presences more significantly in the ERT period than regular times. The qualitative findings showed that the courses where teaching presence was high were evaluated as effective by participants even when cognitive and social presences in these courses were relatively low. These findings suggested that course instructors should prioritize planning well-designed online course activities to ensure their teaching presence in times of emergency.
\end{abstract}

Keywords: The community of inquiry framework, mixed-methods design, online learning, COVID-19 semester, structural equation modeling. 


\section{INTRODUCTION}

With the COVID-19 outbreak, all educational institutions worldwide were forced to shift from face-toface education to fully online education. Although some educational institutions had already experienced blended or flipped learning, most schools or universities were unprepared for this abrupt transition because implementing fully-online education on a global scale had not been the case before (Zimmerman, 2020). Hodges et al. (2020) named teaching during the COVID-19 pandemic as Emergency Remote Teaching (ERT) as it started without proper planning. The term ERT is used to refer to the temporary shift from regular modes of teaching to online teaching, which is "quick to set up and is reliably available during an emergency or crisis" (Hodges et al., 2020, para. 13).

A recent study conducted with 897 faculty and administrators at 672 US institutions in the early weeks of the pandemic indicated that many colleges switched to new teaching techniques and/or delivery modes during the ERT period following the COVID-19 outbreak (Johnson et al., 2020). They also reported that they had to revise and adapt their course assignments, assessment tools, and course schedules regardless of whether they had had online teaching experience before. Moreover, most faculty were uncomfortable with virtual classrooms as they were not trained to offer their classes online or had little experience in teaching online (Baker, 2020; Govindarajan \& Srivastava, 2020). Similarly, most students were anxious in the COVID-19 semester as online classes were a completely different way of receiving education for them (Bates, 2020).

The Community of Inquiry (CoI) framework (Garrison et al., 2000) has been used extensively to describe, explain, and improve learners' inquiry processes in online education. The Col framework models inquiry interactions through three elements: social, cognitive, and teaching presences in online learning. Social presence (SP) represents individuals' interactions with other individuals in the online learning community using their reflective thinking. Cognitive presence (CP) involves constructing conceptual knowledge through collaborative inquiry and learning activities carried out by individuals in line with the determined goals in distance learning environments. Teaching presence (TP) addresses how teaching processes can be designed, facilitated, and guided by taking into account learners' SP and CP.

Several studies explored the relationship between the CoI components. Maddrell et al. (2017) reported a positive and high correlation among TP, CP, and SP in their research study conducted with 51 graduate students in five distance education courses at a public university in the US. Garrison et al. (2010) found out that how students perceived TP was a strong predictor of CP and significantly shaped students' perception of SP. TP significantly predicted both CP $(\beta=.52)$ and SP $(\beta=.51)$ (Garrison et al., 2010). RockinsonSzapkiw et al. (2016) asserted that TP $(\beta=.51)$ was the strongest predictor of student achievement in an online course compared to SP $(\beta=.32)$ and $\mathrm{CP}(\beta=.19)$. Horzum's (2015) study showed that both TP $(\beta$ $=.20)$ and $\mathrm{CP}(\beta=.28)$ were significant predictors of the participants' perceived learning. Similarly, Choo et al. (2020) found that TP $(\beta=.28)$ and $\mathrm{CP}(\beta=.32)$ mainly determined online course evaluations, but not SP $(\beta=.07)$ in their study conducted with 223 undergraduate students at a public university in the US during three semesters.

\section{PURPOSE OF THE STUDY}

As previous studies show, TP is the most determining element of students' online learning experiences in regular online education. Yet, no research examined students' learning experiences during the ERT period (COVID-19 semester) through the lens of the CoI framework. The purpose of this study is to validate the factor structure of the Community of Inquiry (CoI) framework in the COVID-19 semester (Spring 2020) using both quantitative and qualitative data. The research questions that guided this study are as follows:

1. To what extent do the student data collected during the ERT period fit into the CoI framework?

2. To what extent does TP predict CP and SP during the ERT period?

3. What CoI indicators are present in online courses during the ERT period? 


\section{MATERIALS AND METHODS}

This study was designed as an explanatory sequential mixed-method study (Creswell \& Plano Clark, 2018). First, quantitative data were collected using the CoI survey (Arbaugh et al., 2008) and analyzed. Later, qualitative data were obtained with semi-structured interviews and analyzed to explain quantitative results.

\section{Participants and Context}

Participants were selected from a public English-medium university in Turkey. The CoI survey (Arbaugh et al., 2008) was sent via e-mail to undergraduate students in the faculties of education, arts and sciences, economics and administrative sciences, and the school of applied sciences. 745 students responded to the survey; $29 \%$ freshmen, $26 \%$ sophomore, $24 \%$ junior, and $21 \%$ senior. $49 \%$ of the students that responded to the survey were from the faculty of arts and sciences; $22 \%$ of the students were from the faculty of education; $20 \%$ of them were from economics and administrative sciences, and $9 \%$ of the students were from the school of applied sciences. Participants' age ranged from 18 to 22. In structural equation modeling analyses, a large sample size is recommended (Browne \& Sugawara, 1996; Ullman, 2001). In the current study, the ratio of sample size and the number of questionnaire items was 21.91; thus, the sample size was acceptable. We purposefully selected 18 participants among 31 volunteers for interviews through maximal variation sampling (Creswell, 2012) to represent different university programs in the dataset (see Table 1).

Table 1. Details about the Interview Participants

\begin{tabular}{cccc}
\hline Participant ID & Gender & Grade Level & Department \\
\hline 1 & Male & Sophomore & Mathematics \\
2 & Female & Senior & Primary Mathematics Education \\
3 & Female & Freshman & Management and Information Systems \\
4 & Male & Senior & Foreign Language Education \\
5 & Female & Sophomore & Translation and Interpreting Studies \\
6 & Male & Freshman & Turkish Literature and Language \\
7 & Female & Junior & Chemistry \\
8 & Male & Sophomore & Psychology \\
9 & Male & Senior & Management and Information Systems \\
10 & Female & Freshman & Molecular Biology and Genetics \\
11 & Male & Junior & Economics \\
12 & Male & Sophomore & Linguistics \\
13 & Female & Senior & Secondary Mathematics Education \\
14 & Female & Sophomore & Primary Mathematics Education \\
15 & Female & Sophomore & Economics and Management \\
16 & Female & Senior & Psychology \\
17 & Male & Senior & International Trade \\
18 & Female & Senior & Sociology \\
\hline
\end{tabular}

\section{Data Collection Procedures}

The CoI survey (Arbaugh et al., 2008), which contains a 5-point Likert scale for in total 34 TP, SP, and CP items, was administered in English via a web-based form. Participants were asked to fill out the survey by considering their most effective online course(s) in the COVID-19 Spring semester. They also filled out a web-based form to volunteer for interviews after completing the CoI survey. Semi-structured interviews with open-ended questions were conducted with volunteers to explore what TP, CP, and SP indicators (Garrison et al., 2000) emerged in the online courses participants took. The interview protocol included 
seven main questions, along with several sub-questions focusing on students' learning and interactions with their peers and instructors, such as, "How would you evaluate your communication and interaction with your classmates/instructor?" and "How would you evaluate your learning experiences?"

\section{Data Analysis}

\section{Quantitative Data Analysis}

The original CoI survey was developed by Arbaugh et al. (2008) to measure three dimensions: TP, CP, and SP. They used exploratory factor analysis to develop the survey. Arbaugh et al. (2008) reported that the instrument's internal consistency was 0.94 for TP, 0.91 for SP, and 0.95 for CP. In the present study, the reliability of the collected data was analyzed based on Cronbach's alpha coefficient. A Cronbach's alpha value between 0.70 and 0.80 is considered "acceptable," between 0.80 and 0.90 is considered "good," and above 0.90 is considered "excellent" (George \& Mallery, 2003). SPSS version 25.0 was used to estimate the alpha coefficient.

A confirmatory factor analysis was used to evaluate whether the proposed structure fits into the participants' responses. The three-dimensional structure was tested using weighted least squares means and variance adjusted (WLSMV) estimation method as the survey items provided ordinal data. The model fit was evaluated using root mean square error of approximation (RMSEA), comparative fit index (CFI), and Tucker-Lewis index (TLI). An RMSEA value of less than 0.08 and CFI and TLI values higher than 0.95 are considered a good fit for the data (Browne \& Cudeck, 1993; Hu \& Bentler, 1998; Kline, 2010). Mplus 7.2 (Muthen \& Muthen, 2013) was used to conduct a confirmatory factor analysis.

By extending the measurement model tested by confirmatory factor analysis, the extent TP predicted SP and CP was examined in a structural equation model. TP was hypothesized to predict both CP and SP simultaneously. Standardized regression coefficients were reported and evaluated. Mplus 7.2 (Muthen \& Muthen, 2013) was used to conduct the structural equation modeling analysis. Additionally, by randomly splitting the data in half and estimating the model fit and regression coefficients twice, the cross-validity of the results was tested. In the dataset, there were no missing values. Acknowledging that any significant relationship in a structural equation model does not mean a causality between independent and dependent variables, we also analyzed the qualitative data collected through semi-structured interviews.

\section{Qualitative Data Analysis}

Before the data analysis, the first and second authors reviewed the CoI framework together. The authors employed Boyatzis' (1998) hybrid approach to thematic analysis for the qualitative data. The first author created a coding scheme that included codes drawn from the literature of online education and the CoI framework. Afterwards, they analyzed three interviews together and created emerging codes generated from the data. In the second cycle of coding, each author coded seven interviews individually. Finally, they discussed analyses to reach a consensus on developing a codebook. After the authors completed individual coding based on the codebook, they compared the codes from four interviews through data parsing (Watkins, 2017). There were 140 codes from the four interviews. Out of 140, 14 codes were changed or revised, and 11 codes were deleted. Following this ultimate consensus, the codes that included similar topics were collected under categories. Trustworthiness was ensured using several techniques that are for enhancing credibility (Lincoln \& Guba, 1985). Researcher triangulation was provided by having two researchers who coded the data independently and discussed the resulting codes to reach a consensus. Additionally, an experienced qualitative researcher not involved in data coding was involved in peer-debriefing by reviewing the emerging themes and providing feedback. 


\section{FINDINGS}

\section{Quantitative Findings}

\section{The Reliability of the Survey Data}

The data's reliability was evaluated based on Cronbach's alpha coefficient, calculated as 0.98 for TP, 0.94 for SP, and 0.97 for CP dimensions. These values indicated excellent internal consistency of the data (George \& Mallery, 2003).

\section{The Confirmatory Factor Analysis}

The factor structure of the CoI survey was evaluated by conducting confirmatory factor analysis. As the original instrument proposed a three-dimensional structure, the extent to which participant responses supported the three-dimensional structure was tested (see Figure 1). The confirmatory factor analysis results reported in Table 2 showed that the data fitted the three-dimensional structure very well (RMSEA $\leq .08$., TLI $\geq .95$, CFI $\geq .95$ ). The standardized factor loadings of questionnaire items ranged from .86 to .96 for TP; .80 to .93 for SP; and .82 to .93 for CP. All of these correlations between items and factors were significant $(\mathrm{p}=<.01)$.

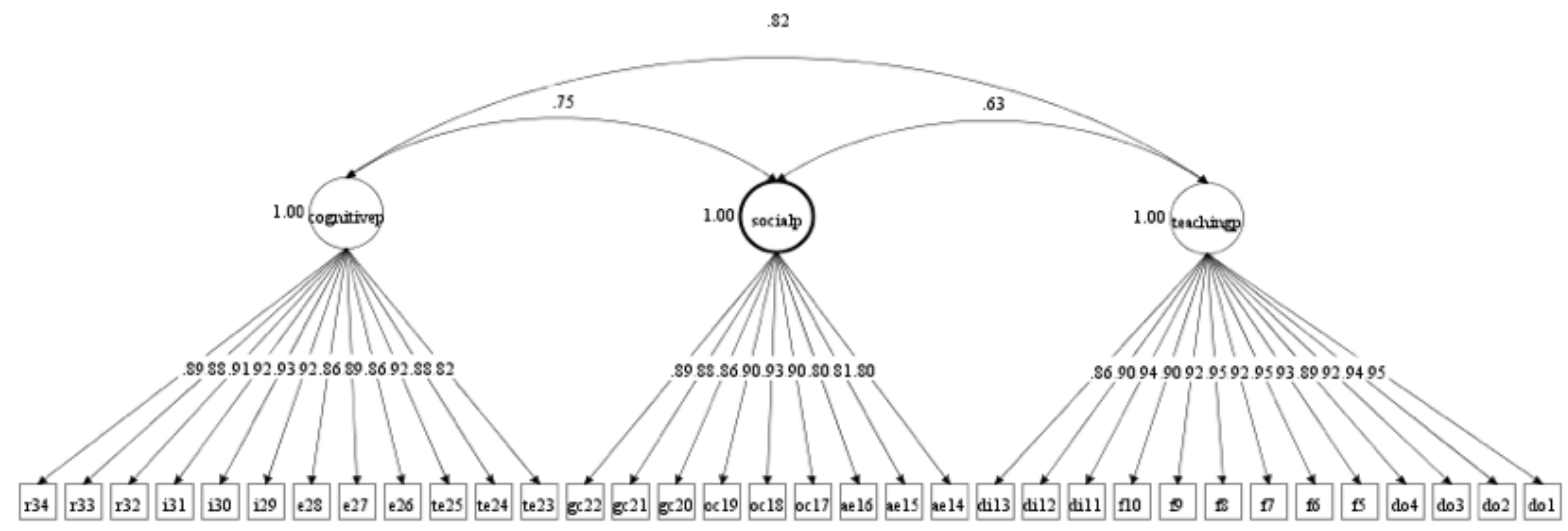

Figure 1. The measurement model of the Col instrument

Table 2. Confirmatory Factor Analysis Results

\begin{tabular}{cccccc}
\hline$X^{2}$ & df & $X^{2} / d f$ & TLI & CFI & $\begin{array}{c}\text { RMSEA } \\
(90 \% \text { Cl) }\end{array}$ \\
\hline 2897.01 & 524 & 5.53 & .974 & .976 & $\begin{array}{c}.078 \\
(.075-.081)\end{array}$ \\
\hline
\end{tabular}

Note: $X^{2}=$ Chi-square, $d f=$ degrees of freedom, $T L I=$ Tucker Lewis index, CFI = comparative fit index, RMSEA = root mean square error of approximation; $\mathrm{Cl}=$ confidence interval.

\section{Predicting SP and CP by TP}

TP was hypothesized to predict both SP and CP based on the literature. The present study results also showed that TP could significantly predict both SP $(\mathrm{p}=<.01)$ and CP $(\mathrm{p}=<.01)$. This means that when there was a high level of TP, SP and CP were also high, and when there was a low level of TP, SP and CP were low. As shown in Figure 2, the relationship between TP and CP $(\beta=.82)$ was stronger than the relationship between TP and SP $(\beta=.63)$. Overall, TP scores explained $40 \%$ of the variance in SP scores and $67 \%$ of the variance in $\mathrm{CP}$ scores. 


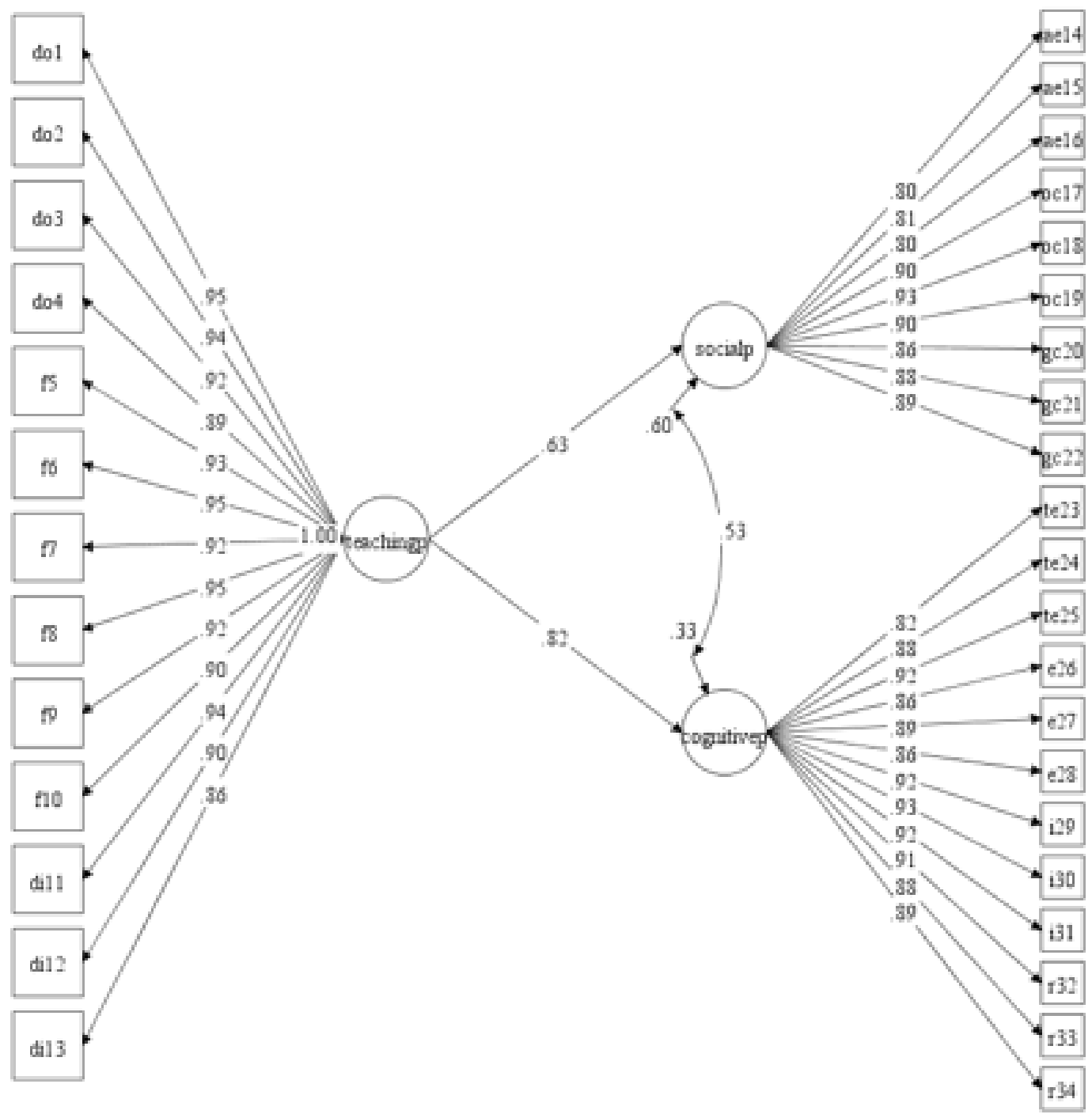

Figure 2. Predicting SP and CP by TP

\section{Cross-Validating Measurement Model and Structural Equation Modeling Results}

The data were split randomly. The model fit indices and the regression coefficients were estimated, and the results were compared. The confirmatory factor analysis results showed that the hypothesized threedimensional model had a good fit for both random samples of data.

The structural equation modeling results showed that TP could significantly predict both $S P(p=<.01)$ and CP $(\mathrm{p}=<.01)$ by random samples. Similar to the original data, the relationship between TP and CP (Sample1 $\beta=.83$; Sample2 $\beta=.81$ ) was stronger compared to the relationship between TP and SP (Sample1 $\beta=.65$; Sample $2 \beta=.61$ ). Overall, TP scores explained $42 \%$ (sample1) and $37 \%$ (sample2) of the variance in SP scores, and 68\% (sample1) and 66\% (sample2) of the variance in CP scores (see Table 3). 
Table 3. Cross-Validation of Confirmatory Factor Analysis Results

\begin{tabular}{ccccccc}
\hline & $x^{2}$ & $\mathrm{df}$ & $\mathrm{X}^{2} / \mathrm{df}$ & $\mathrm{TLI}$ & $\mathrm{CFI}$ & $\begin{array}{c}\text { RMSEA } \\
(90 \% \mathrm{Cl})\end{array}$ \\
\hline Sample1 & 1634.64 & 524 & 3.12 & .979 & .981 & $\begin{array}{c}.075 \\
(.071 ; .079) \\
\text { Sample2 }\end{array}$ \\
& 1608.35 & 524 & 3.07 & .974 & .975 & $\begin{array}{c}.075 \\
(.071 ; .079)\end{array}$ \\
\hline
\end{tabular}

Note: $X^{2}=$ Chi-square,$d f=$ degrees of freedom, $T L I=$ Tucker Lewis index,$C F I=$ comparative fit index, $R M S E A=$ root mean square error of approximation; $\mathrm{Cl}=$ confidence interval.

\section{Qualitative Findings}

Interviews were analyzed to identify the three main elements of the CoI framework and obtain a deeper understanding of how these were related to each other in online classes in the COVID-19 semester.

\section{TP Indicators}

Our findings pointed out several important factors affected participants' perception of high TP in their courses. In terms of TP elements, interview participants highlighted the importance of effective course design and organization, facilitating discourse, and assessment and evaluation.

Regarding effective design and organization, all interview participants emphasized the importance of having live class sessions and accessing course materials promptly. Participants found several instructional strategies effective in terms of the design and organization of the courses during the ERT period. For instance, synchronous discussions, small group activities, and writing and sharing reflections were effective instructional strategies listed by the participants. As most of the interview participants indicated, having access to course materials (e.g., lecture videos, presentations, or readings) before live sessions helped them to better prepare for class activities. Additionally, participants reported that they engaged in the courses where they studied the materials beforehand more and were more active during live class sessions. A few participants added that they could not attend live classes because of technical problems. Yet, they could still catch up with the courses when the instructors shared session recordings or course materials right after live sessions. Our interview data indicated that TP was also high in the courses where the instructors facilitated discourse by asking guiding questions, encouraging students' queries and participation, and keeping discussions focused on the topic. In addition, some of the interview participants stated that they found courses more effective when the course instructors provided prompt communication and obtained students' input about course activities (e.g., revising the syllabus).

In terms of assessment and evaluation, participants mentioned that they found authentic assessment opportunities more effective. Additionally, they emphasized that weekly quizzes or practice tests helped them maintain their course engagement and learn the content more easily. Participants also pointed out that the traditional evaluation methods (e.g., invigilated exams) usually resulted in unfair assessment in online settings. They suggested that open-book exams, group projects, and take-home written exams could be alternative assessment methods in online education. Table 4 presents the TP indicators that emerged from the data with the sample excerpts. 


\section{CP Indicators}

Our findings indicated that participants' $\mathrm{CP}$ was high in the courses where the instructor used authentic assessment tools, such as hands-on projects and/or provided authentic content by making it relatable to students' daily life. Participants became cognitively present when the instructor asked questions and held whole-class discussions over the authentic content. Additionally, participants reported that when they read their classmates' messages in the chat during live sessions or comments in online discussion forums, they were challenged to think about the topic being discussed from different perspectives. As most of the interviewees indicated, having access to everyone's comments in an online learning environment enhanced their learning. The present study findings clearly demonstrated that there is an interplay between authentic content, authentic assessment, and comments/ideas visible to everyone and CP in online learning settings during the ERT period (see Table 5).

\section{SP Indicators}

In terms of SP, participants highlighted the importance of open communication with instructors, community building with other students, and peer interaction. As for open communication, all participants emphasized that they were more socially present and actively participated in classes when the instructor designed the course in collaboration with students. In addition, when community building was encouraged through course activities, participants felt more engaged in lessons and shared their opinions and ideas easily. The findings also showed that the more peer interaction was incorporated into class activities, the more socially present participants became. This resulted in their active participation and high engagement in online classes. It can be inferred that whether instructors kept communication and interaction with and among students constant determined how SP emerged in online courses during the ERT period (see Table 6). 


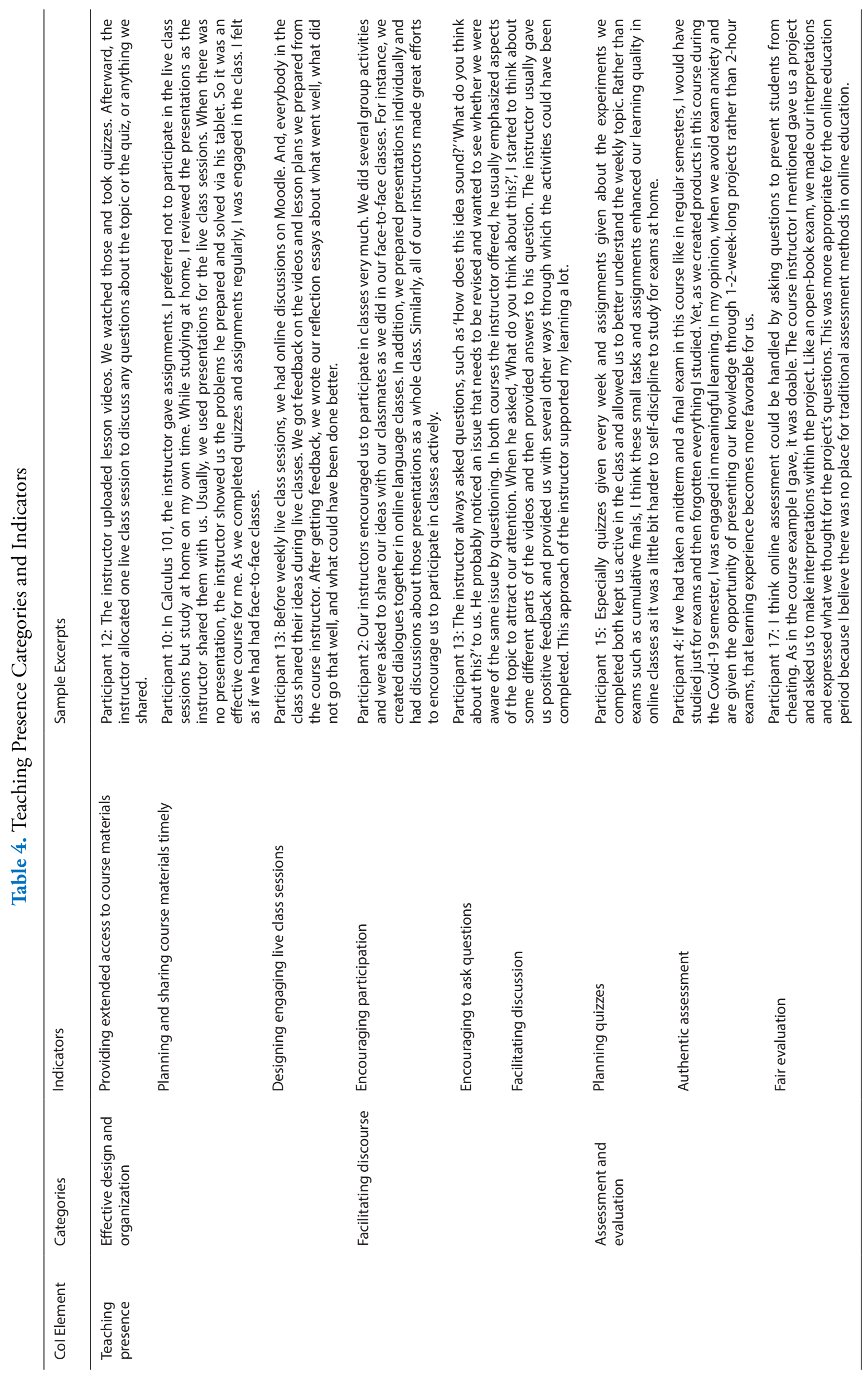




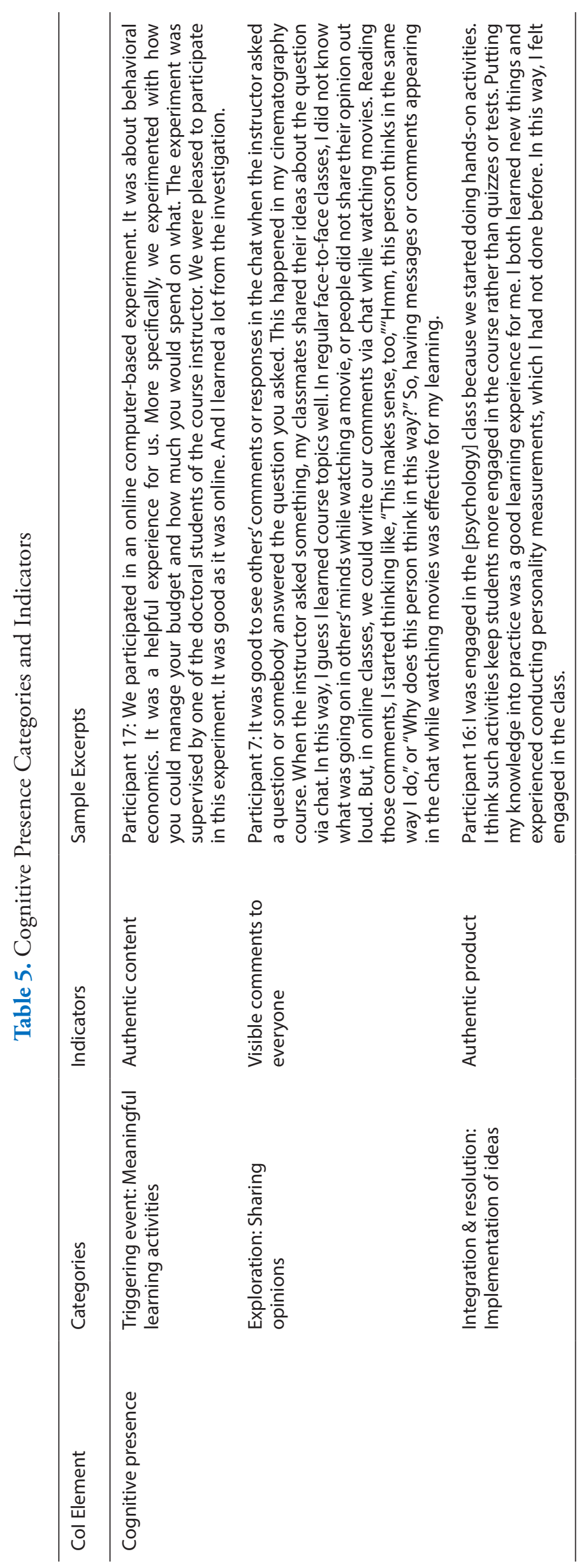




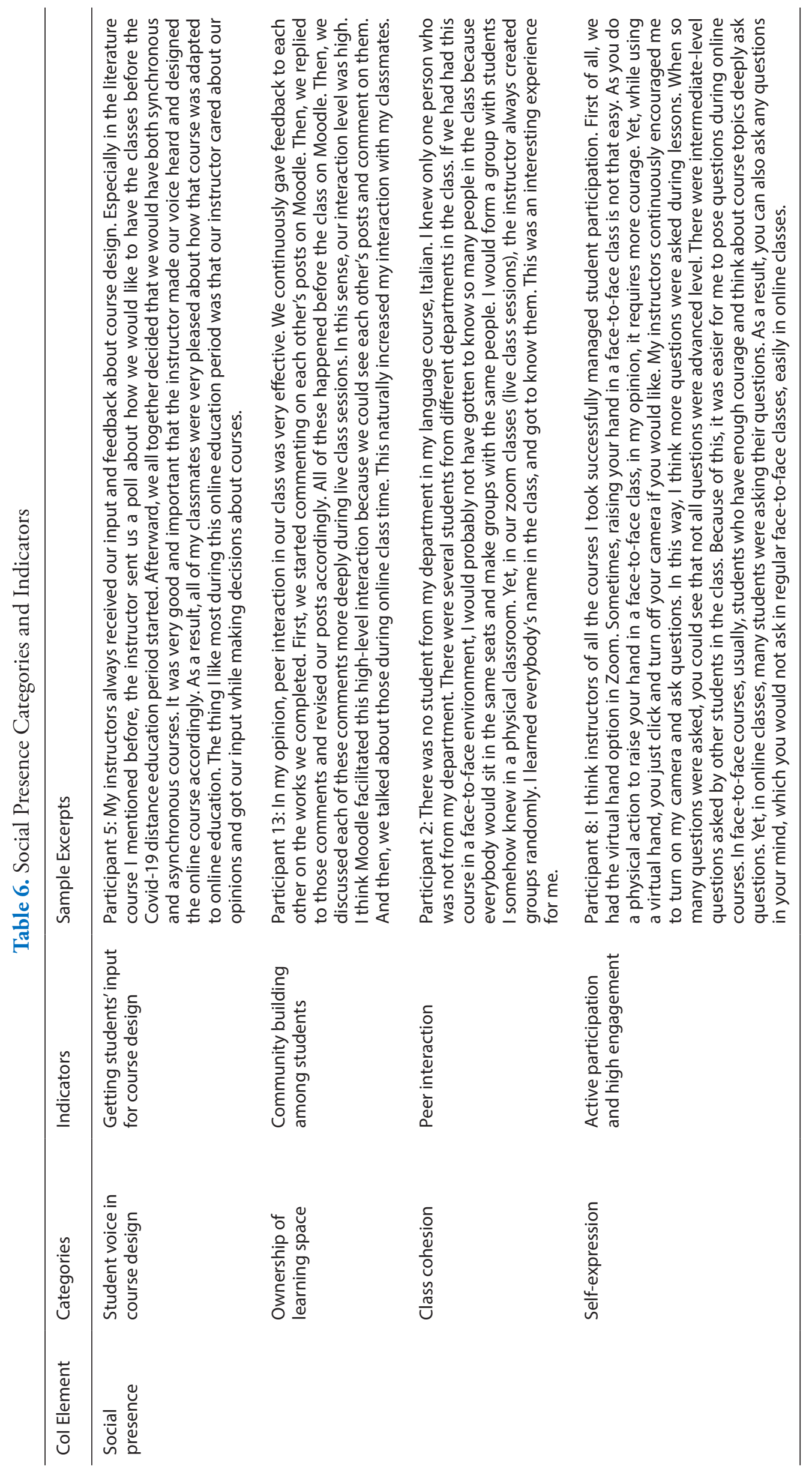




\section{How TP Relates to CP and SP during the ERT Period}

Our qualitative data analysis exemplifies how the relation between TP, CP, and SP unfolded in online classes during the COVID-19 semester. Qualitative data analysis yielded 229 codes for TP, 111 codes for SP, and 59 codes for CP. In the interviews, when participants were asked which course was the most effective one during the COVID-19 semester, they mainly discussed what the instructor did during the classes and how he/she designed live class sessions and online assessments, which are TP indicators.

To illustrate how the CoI elements interacted with each other during the ERT period, we reported the qualitative findings based on the following relations: TP and CP, TP and SP, and SP and CP. To explore the relation between TP and CP, we examined all the indicators and found that some aligned with each other. When the instructors integrated authentic content into their live class sessions by creating meaningful learning activities and facilitated discussions, the sessions became more engaging for students, and more $\mathrm{CP}$ was observed. For instance, Participant 10 highlighted that as the instructor made connections with students' lives through authentic materials, the course became very engaging for her.

In the course that was most efficient for me, the last topic we discussed was "Women as OtherFeminism." We were assigned to read a few related articles, and the instructor brought the songs and poems that belong to that period to the class. As it was a social studies course, the instructor asked several questions, such as "What do you think about this?" "Do you think this is adaptable to our current world?" "If it was adapted to our current lives, how would you integrate it into your own lives?" and "How do you perceive this?" for instance, we also discussed a movie that we watched as a whole class, and the instructor asked several related questions to us. In this way, I think the course instructor aimed to engage us in the course content.

The last category of TP is assessment and evaluation. One of the indicators of this category is authentic evaluation, and this aligns with authentic products in the category of CP (see Table 5). To clarify, when students create an authentic artifact that they may use in their real lives, high CP can be observed. For example, when questions about learning activities were asked during the interview, Participant 4 explained how he had developed authentic products for his final projects, such as a game to teach the topic of gerund and infinitives and lesson plans for English language teaching, instead of midterms or finals.

I designed a computer-based game to teach English to Turkish students in one of my courses. Keeping the question "How could I teach gerunds and infinitives effectively?" in mind, I designed a game for one month using a software program. In my departmental course, I prepared a lesson plan to teach an English grammar topic. I selected the topic and the theme for this lesson plan. I developed the lesson plan completely based on the course textbook and the course instructor's template.

Our findings also show that TP and SP were related in that instructors' design of group works and wholeclass or small-group discussions facilitated community building among students particularly when switched to online learning rapidly. Participant 18 gave an example of how the instructor assigned a group work to prepare students for online classes right after the COVID-19 outbreak:

The instructor grouped us in my language course and assigned us to prepare presentations right after the COVID-19 outbreak. She asked us to contact our groupmates and set up WhatsApp groups to keep class communication active and support each other in the transition period. Usually, I don't like group work, but this one worked well for me because we could prepare for classes together.

When it comes to the relation between SP and CP, it can be argued that peer interaction and peer feedback interacted with students' CP. Participant 2 explained how she had used her classmates' feedback to revise her work in her teaching practicum course elaborately:

My most positive experience during the COVID-19 semester was when we were assigned to record videos to teach lessons individually in my educational sciences courses. After uploading the videos to Moodle, we had synchronous class discussions and commented on each other's videos. In my opinion, we learned a lot during these discussions because we noticed what had been missing in the videos 
and thought about how we could improve ourselves. I felt better when I received feedback from my peers because only the course instructor would observe the lessons I teach in our regular face-to-face classes. Yet, I shared my video with everyone in the class, and they could watch it individually in the COVID-19 semester. I received lots of feedback. Having the opportunity to get feedback from my peers and comment on their videos was useful.

These qualitative findings supported the claim that TP was the main CoI element that facilitated SP and CP even during the ERT period. SP and CP also interacted with each other in the courses where peer interaction and peer feedback were encouraged.

\section{DISCUSSION}

Previous studies that analyzed the relationships among the CoI framework elements found that more $\mathrm{CP}$ and SP were observed with higher TP, and TP strongly predicted both SP and CP in online classes (Akyol \& Garrison, 2008; Caskurlu et al., 2020; Garrison et al., 2010; Horzum, 2015; Rockinson-Szapkiw et al., 2016). Parallel with these research findings, the current study's quantitative results also confirm that TP is a significant predictor of SP and CP. Compared to the previous research conducted in regular online learning environments, however, the present study shows that TP became even a stronger factor that shapes students' online learning experiences in terms of CP and SP during the ERT period. In the current study, TP significantly predicted both $\mathrm{CP}(\beta=.82)$ and SP $(\beta=.63)$. TP scores explained $40 \%$ of the variance in SP scores and $67 \%$ of the CP scores variance. In Garrison et al. (2010)'s study, which was conducted in a regular online learning setting, TP was less strong in terms of predicting $\mathrm{CP}(\beta=.52)$ and $\mathrm{SP}(\beta=.51)$.

The qualitative findings of the current study also align with the result that TP was a strong predictor of CP and SP during the COVID-19 semester. When instructors encouraged student participation, facilitated discussion, and incorporated authentic content into their courses, which are TP indicators, students actively became involved in the learning process, becoming more cognitively present, as put forward by researchers (Fiock, 2020; Johnson, 2014; Sorensen \& Baylen, 2009). Moreover, when students were encouraged to participate in whole-class discussions and share their ideas, they were likely to view discussion topics from different perspectives, which involves CP (Arbaugh, 2012; Garrison et al., 2010). Similarly, enacting TP by encouraging student participation in discussions also interacted with students' SP. Due to the instructor's scaffolding student participation through questions, students were involved in peer interaction and became engaged in the course, which are SP indicators (Lowenthal, 2010; Tu \& McIsaac, 2002). Another example of the relation between TP and SP is that instructors' design of group works or discussions enhanced the sense of community among students, particularly after the rapid transition to online education in the COVID-19 semester (Rovai, 2000; Stephens \& Roberts, 2017). Peer interaction is the basis of the relation between SP and CP. When peer interaction was promoted during live class sessions or peer feedback was received and given on an online discussion forum asynchronously, students gained different perspectives. They also made a cognitive effort to revise their work based on peer feedback (Fiock, 2020).

The qualitative findings also revealed that whether instructors adapted their courses to online modality, reconsidered assessment tools for online teaching, remained accessible during and after live class sessions, and obtained students' feedback about course activities relate to the extent of students' perceptions of CP and SP in those classes. While all these can be considered under TP, they are all specific to the instructor and determine the instructor social presence. Being at the intersection of TP and SP, instructor social presence is regarded as an aspect of TP (Borup et al., 2012; Swan \& Shih, 2005). Therefore, while quantitative results pointed at TP as the strongest predictor for CP and SP, qualitative analyses highlighted that a subset of TP, instructor social presence, appeared to be one of the strongest elements that determined the perceived quality of online/remote courses during the COVID-19 semester. 


\section{CONCLUSION}

The findings of the present study suggest that course instructors should prioritize planning activities to ensure TP when designing online courses in times of emergency or under similar conditions. In recent years, schools have been closed due to several natural disasters, such as earthquakes, hurricanes, or fires (Barbour et al., 2020). While there is hope that the COVID-19 threat soon is diminished, the emergencies that require an immediate shift to online education will remain present. Therefore, it becomes important to identify factors that will increase the quality of online education in times of emergencies.

The findings should be interpreted within limitations. First, the study was conducted with a sample of undergraduate students at a public university from various faculties. However, probability sampling was not implemented, and the sample included participants from a single university, although the sample size was large. Therefore, the generalizability of the findings is limited. Second, the data sources of this mixed-method study were the CoI survey and qualitative semi-structured interviews. Even though the CoI survey and the interviews provided the relevant data on students' perceptions of the CoI elements in different online courses, we could not observe any online classes during the ERT period or collect any course materials, syllabi, and students' exams or projects.

\section{Suggestions for Further Research and Practice}

Providing guidelines, this study may help instructors and instructional designers to understand students' expectations in similar conditions and design interactive, engaging, and meaningful learning environments in the future. Our findings shed some light on how TP, SP, and CP can be enhanced in online courses. We found that keeping connection and communication with their instructors and peers was important for students during the ERT period, while most distance education is designed for asynchronous modalities. Designing synchronous lessons and tasks to support interaction between students and instructors plays a crucial role in keeping students engaged in the learning process. It is also important to note that effective use of learning management systems (LMSs) to provide course materials and activities seemed essential to establish high TP. In addition, using LMSs effectively to hold whole-class asynchronous discussions or to let students provide peer feedback could enhance both CP and SP during the ERT period.

Given that it has been almost two years since the COVID-19 outbreak, what kind of teaching practices have been adapted by faculty members and how they have integrated the CoI indicators into their lessons could be investigated. Within the scope of the present study, most faculty members' use of technological tools was limited as a rapid transition to online teaching occurred in the COVID-19 semester. With the growing number of technological tools to facilitate students' collaboration and interaction, there are many other effective uses of technology to support TP, CP, and SP in online or blended courses. Thus, further research can explore TP, CP, and SP in settings where fully-online or blended courses are offered in the current postERT period, focusing on the role of effective technology use for synchronous and asynchronous tasks.

Authors' Note: This research was funded by Research Grant Award No. 20D02P1 from Bogazici University Scientific Research Projects Fund. The opinions, findings, and conclusions do not reflect the views of the funding agencies, cooperating institutions, or other individuals.

A part of this paper was presented at the 19th Biennial EARLI Conference in Gothenburg, Sweden (virtual) in August 2021.

Acknowledgements: We would like to thank Dilek Turan, Elif Cil, Ezgi Diri, Fatma Seyh, Gozde Doguer, Rumeysa Akar for their help with the interview transcriptions. 


\section{BIODATA and CONTACT ADDRESSES of AUTHORS}

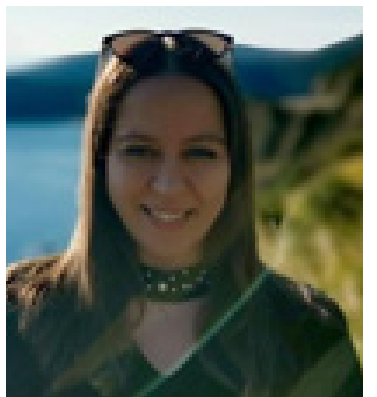

Mutlu SEN-AKBULUT is an assistant professor in the Department of Computer Education and Educational Technology at Bogazici University. She completed her Ph.D. at the University of Georgia, USA, in the area of Learning, Design, and Technology. Her research interests include the design and development of technology-enhanced learning environments, 21-st century skills and technology integration, and constructivist pedagogies for teacher education.

Mutlu SEN-AKBULUT

Department of Computer Education and Educational Technology, Faculty of Education Address: Bogazici University, 34342, Istanbul, Turkey

Phone: +90 2123596789

E-mail: mutlu.sen@boun.edu.tr

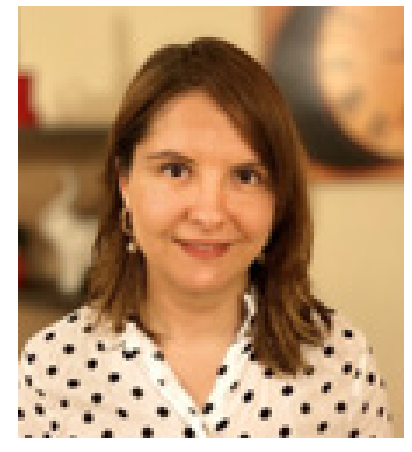

Duygu UMUTLU is an assistant professor at the Department of Computer Education and Educational Technology at Bogazici University, Turkey. As a Fulbright scholar, she received her Ph.D. in Learning, Design, and Technology program at the University of Georgia, USA. She received her M.A. degree in Educational Technology program, Bogazici University, Turkey. She has been involved in several international and national research projects so far. Her current research interests are innovative teacher education, technology integration for meaningful learning, pre-service teacher education for programming, debugging during programming, and digital adaptive scaffolding.

\section{Duygu UMUTLU}

Department of Computer Education and Educational Technology, Faculty of Education Address: Bogazici University, 34342, Istanbul, Turkey

Phone: +90 2123597510

E-mail: duygu.umutlu@boun.edu.tr

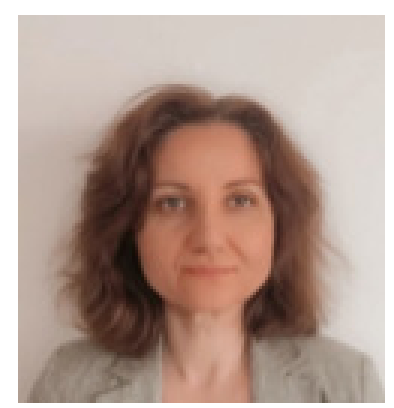

Diler ONER is the director of the Center for Teaching and Learning and a faculty member at the Department of Computer Education and Educational Technology at Bogazici University in Istanbul. She received her MSc. and Ph.D. from the University of Wisconsin-Madison, Department of Curriculum and Instruction. Her research focuses on designing, developing, and implementing computer-based tools to support higher-level thinking skills both for students and teachers.

\section{Diler ONER}

Department of Computer Education and Educational Technology, Faculty of Education Address: Bogazici University, 34342, Istanbul, Turkey

Phone: +90 2123597311

E-mail: diler.oner@boun.edu.tr 


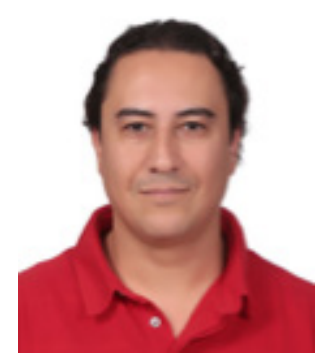

Serkan ARIKAN is an associate professor in the Department of Mathematics and Science Education at Bogazici University. He completed his Ph.D. at the METU, Turkey. His research interests include measurement and evaluation in education, test development, computerized adaptive tests, non-routine problems, differential item functioning and measurement invariance. He is the principal investigator of BounAdaptiveTestLab.

Serkan ARIKAN

Department of Mathematics and Science Education, Faculty of Education

Address: Bogazici University, 34342, Istanbul, Turkey

Phone: +90 2123597032

E-mail: serkan.arikan1@boun.edu.tr

\section{REFERENCES}

Akyol, Z., \& Garrison, D. R. (2008). The development of a community of inquiry over time in an online course: Understanding the progression and integration of social, cognitive and teaching presence. Journal of Asynchronous Learning Networks, 12, 3-22. https://doi.org/10.24059/olj.v12i3.66

Arbaugh, J. B. (2012). Does academic discipline moderate CoI-course outcomes relationships in online MBA courses? The Internet and Higher Education, 17(1), 16-28. doi:10.1016/j.iheduc.2012.10.002

Arbaugh, J. B., Cleveland-Innes, M., Diaz, S. R., Garrison, D.R., Ice, P., Richardson, \& Swan, K.P. (2008). Developing a community of inquiry instrument: Testing a measure of the Community of Inquiry framework using a multi-institutional sample. The Internet and Higher Education, 11(3-4), 133136. https://doi.org/10.1016/j.iheduc.2008.06.003

Baker, V. L. (2020, March 25). How colleges can better help faculty during the pandemic. Inside Higher Ed. https://www.insidehighered.com/views/2020/03/25/recommendations-howcolleges-canbetter-support-their-faculty-during-covid-19

Barbour, M. K., LaBonte, R., Kelly, K., Hodges, C., Moore, S., Lockee, B., Trust, T., Bond, A., \& Hill, P. (2020). Understanding Pandemic Pedagogy: Differences Between Emergency Remote, Remote, and Online Teaching. https://k12sotn.ca/blog/announcing-special-report-understandingpandemic-pedagogy-differences-between-emergency-remote-remote-and-online-teaching/ Accessed on December 23, 2020.

Bates, T. (2020, April 7). What should we be doing about online learning when social distancing ends? Online Learning and Distance Education Resources. https://www.tonybates.ca/2020/04/07/ what-should-we-be-doing-about-online-learningwhen-social-distancing-ends/

Borup, J., West, R. E., \& Graham, C. R. (2012). Improving online social presence through asynchronous video. The Internet and Higher Education, 15, 195-203. https://doi.org/10.1016/j.iheduc.2011.11.001

Boyatzis, R. E. (1998). Transforming qualitative information: Thematic analysis and code development. Thousand Oaks, CA: Sage publications.

Browne, M. W., \& Cudeck, R. (1993). Alternative ways of assessing model fit. In K. A. Bollen \& J. S. Long (Eds.), Testing structural equation models (pp. 136-162). Beverly Hills, CA: Sage.

Browne, M. W., \& Sugawara, H. M. (1996). Power analysis and determination of sample size for covariance structure modeling. Psychological Methods, 1(2), 130-149. https://doi.org/10.1037/1082989x.1.2.130

Caskurlu, S., Maeda, Y., Richardson, J. C., \& Lv, J. (2020). A meta-analysis addressing the relationship between teaching presence and students' satisfaction and learning. Computers \& Education, 157, 103966. https://doi.org/10.1016/j.compedu.2020.103966 
Choo, J., Bakir, N., Scagnoli, N. I., Ju, B., \& Tong, X. (2020). Using the Community of Inquiry Framework to Understand Students' Learning Experience in Online Undergraduate Business Courses. TechTrends, 64(1), 172-181. https://doi.org/10.1007/s11528-019-00444-9

Creswell, J. W. (2012). Educational research: Planning, conducting, and evaluating quantitative and qualitative research (4th ed.). Upper Saddle River, NJ: Prentice-Hall.

Creswell, J. W., \& Plano Clark, V. L. (2018). Designing and conducting mixed methods research. Thousand Oaks, CA: Sage publications.

Fiock, H. (2020). Designing a community of inquiry in online courses. The International Review of Research in Open and Distributed Learning, 21(1), 135-153. https://doi.org/10.19173/irrodl.v20i5.3985

Garrison, D. R., Anderson, T., \& Archer, W. (2000). Critical Inquiry in a Text-Based Environment: Computer Conferencing in Higher Education. The Internet and Higher Education, 2(2-3), 87105. https://doi.org/10.1016/s1096-7516(00)00016-6

Garrison, D. R., Cleveland-Innes, M., \& Fung, T. S. (2010). Exploring causal relationships among teaching, cognitive and social presence: Student perceptions of the community of inquiry framework. The Internet and Higher Education, 13(1-2), 31-36. https://doi.org/10.1016/j.iheduc.2009.10.002

George, D., \& Mallery, P. (2003). SPSS for windows step by step: A simple guide and reference (11.0 update) (4th ed.). Boston, MA: Allyn \& Bacon.

Govindarajan, V., \& Srivastava, A. (2020, March 31). What the shift to virtual learning could mean for the future of higher ed. Harvard Business Review. https://hbr.org/2020/03/whatthe-shift-to-virtuallearning-could-mean-for-the-future-of-higher-ed

Hodges, C., Moore, S., Lockee, B., Trust, T., \& Bond, A. (2020). The difference between emergency remote teaching and online learning. EDUCAUSE Review, 3. https://er.educause.edu/articles/2020/3/ the-difference-between-emergency-remote-teaching-and-online-learning. Accessed on June $11,2020$.

Horzum, M. B. (2015). Online learning students' perceptions of the community of inquiry-based on learning outcomes and demographic variables. Croatian Journal of Education: Hrvatski casopis za odgoj i obrazovanje, 17(2), 535-567. https://doi.org/10.15516/cje.v17i2.607

Hu, L. T., \& Bentler, P. M. (1998). Fit indices in covariance structure modeling: Sensitivity to underparameterized model misspecification. Psychological Methods, 3, 424-453. https://doi. org/10.1037/1082-989x.3.4.424

Johnson, N., Veletsianos, G., \& Seaman, J. (2020). US Faculty and Administrators' Experiences and Approaches in the Early Weeks of the COVID-19 Pandemic. Online Learning, 24(2), 6-21. https://doi.org/10.24059/olj.v24i2.2285

Johnson, S. (2014). Applying the seven principles of good practice: Technology as a lever - in an online research course. Journal of Interactive Online Learning, 13(2), 41-50. https://www.ncolr.org/jiol/ issues/pdf/13.2.2.pdf

Kline, R. B. (2010). Principles and practice of structural equation modeling. New York, NY: Guilford Publications.

Lincoln, Y. S. \& E. G. Guba (1985). Naturalistic Inquiry. Newbury Park, CA: Sage.

Lowenthal, P. R. (2010). The evolution and influence of social presence theory on online learning. In T. T. Kidd (Ed.), Social computing: Concepts, methodologies, tools, and applications (pp. 113-128). IGI Global. https://doi.org/10.4018/9781605669847.ch010

Maddrell, J. A., Morrison, G. R., \& Watson, G. S. (2017). Presence and learning in a community of inquiry. Distance Education, 38(2), 245-258. https://doi.org/10.4324/9780429294235-8

Muthen, L. K., \& Muthen, B. O. (2013). Mplus user's guide (Version 6.1) [Computer software and manual]. Los Angeles, CA: Muthen \& Muthen. 
Rockinson-Szapkiw, A., Wendt, J., Whighting, M., \& Nisbet, D. (2016). The predictive relationship among the community of inquiry framework, perceived learning and online, and graduate students' course grades in online synchronous and asynchronous courses. International Review of Research in Open and Distributed Learning, 17(3), 18-35. https://doi.org/10.19173/irrodl.v17i3.2203

Rovai, A. P. (2000). Building and sustaining community in asynchronous learning networks. Internet and Higher Education, 3, 285-297. https://doi.org/10.1016/S1096-7516(01)00037-9

Sorensen, C. K., \& Baylen, D. M. (2009). Learning online: Adapting the seven principles of good practice to a Web-based instructional environment. In A. Orellana, T. L. Hudgins, \& M. Samonson (Eds.), The perfect online course: Best practices for designing and teaching (pp. 69-86). Charlotte, NY: Information Age Publishing.

Stephens, G. E., \& Roberts, K. L. (2017). Facilitating collaboration in online groups. Journal of Educators Online, 14(1), 1-16. Retrieved from https://eric.ed.gov/?id=EJ1133614

Swan, K., \& Shih, L. F. (2005). On the nature of development of social presence in online discussions. Journal of Asynchronous Learning Networks, 9(3), 115-136. https://doi.org/10.24059/olj.v9i3.1788

Tu, C., \& McIsaac, M. (2002). The relationship of social presence and interaction in online classes. The American Journal of Distance Education, 16(3), 131-150. https://doi.org/10.1207/S15389286AJDE1603_2

Ullman, J. B. (2001). Structural equation modeling. In B. Tabachnick \& L. S. Fidell (Eds.), Using multivariate statistics (4th ed., pp.653-771). Boston: Allyn \&Bacon

Watkins, D. C. (2017). Rapid and rigorous qualitative data analysis: The "RADaR" technique for applied research. International Journal of Qualitative Methods, 16(1), 1-9. https://doi. org/10.1177/1609406917712131

Zimmerman, J. (2020). Coronavirus and the great online-learning experiment: Let's determine what our students actually learn online. Chronicle of Higher Education Retrieved June 18, 2020, from https:// www.chronicle.com/article/Coronavirusthe-Great/248216 